УДК 069.444

https://doi.org/10.24852/2587-6112.2021.6.360.368

\title{
МЕТОДИКА КОНСЕРВАЦИИ АРХЕОЛОГИЧЕСКИХ ПРЕДМЕТОВ ИЗ КОЖИ НА ПРИМЕРЕ ФРАГМЕНТОВ ОБУВИ ИЗ АРХЕОЛОГИЧЕСКИХ РАСКОПОК Г. ПЕРМИ 2020 Г.
}

\author{
(C) 2021 г. Н.А. Чурилова
}

В статье представлен обзор методик консервации археологических изделий из кожи, основанный на отечественных публикациях. Обзор охватывает методики середины XX - н. XXI вв. среди которых есть как методики устаревшие и в настоящее время не рекомендованные в научной реставрации археологических изделий из кожи, так и методики, применяемые в наше время, включая методики с применением комбинаций полиэтиленгликолей различных молекулярных масс. На примере консервации деталей кожаной обуви, найденной в ходе археологических раскопок в историческом центре г. Перми в 2020 г. более подробно рассмотрен способ консервации археологической кожи с длительным погружением в раствор высокомолекулярного и низкомолекулярного полиэтиленгликоля с последующей сушкой вымораживанием.

Ключевые слова: археология, предметы из кожи, консервация, полиэтиленгликоль, археологические раскопки в г. Перми.

\section{METHODS OF CONSERVATION OF ARCHAEOLOGICAL LEATHER ARTEFACTSONTHE EXAMPLE OFFRAGMENTSOFSHOESFROMTHE ARCHAEOLOGICAL EXCAVATIONS IN PERM IN 2020.}

\section{N.A. Churilova}

The article presents an overview of the methods of conservation of archaeological leather artefacts based on national publications. The overview covers the methods of the mid XX - early XXI centuries, among which there are both outdated methods which currently are not recommended in the scientific restoration of archaeological leather artefacts and methods used in our time including methods using combinations of polyethylene glycols of different molecular weights. Using the example of the preservation of parts of leather shoes found during archaeological excavations in the historical center of Perm in 2020, the method of conservation archaeological leather with prolonged immersion in a solution of high-molecular and low-molecular polyethylene glycol, followed by freezing drying, is considered in more detail.

Keywords: archeology, leather artefacts, conservation, polyethylene glycol, archaeological excavations in Perm

Археологические предметы, поступающие в музеи, как правило, выполнены из различных материалов. Изделия из кожи, как и другие предметы из органических материалов, в силу своих природных свойств разрушаются быстрее, чем предметы из других материалов. При отсутствии реставраторов, предметы десятилетиями находятся в хранениях в пересушенном состоянии, деформированные, со следами плесени. Такие предметы фактически выведены из научного оборота, т.к. по причине их состояния сохранности исследователи не имеют возможности работать с ними. И уж тем более, эти предметы не доступны обычным посетителям музеев, так как не могут быть включены в экспозиции или представлены на выставках из-за отсутствия экспозиционного вида. Мероприятия, прово- димые в процессе камеральной обработки, также могут нанести вред предметам из-за недостатка знаний и опыта исполнителей.

Выбор методики консервации, важнейшей операции при реставрации археологического предмета, напрямую зависит от состояния сохранности материала, из которого он изготовлен.

Сохранность археологической кожи зависит от особенностей места залегания предмета. Кожа, извлеченная из раскопов, быстро теряет влагу, становится сухой и ломкой (Кимеева, Окунева, 2009, с. 163). Кожа также подвержена негативному влиянию внешних факторов. Кожа содержит белковые вещества, значительное количество жиров и воды, потеря этих веществ делает кожу жесткой и ломкой. В результате этих процессов кожа расслаива- 
ется, ее поверхность покрывается трещинами, может ломаться (Фармаковский, 1947, с. 102). В археологической коже плохой сохранности (сухой, ломкой, рыхлой или тонкой) происходит вымывание дубителей, потеря влаги (дегидратация), обезжиривание. В пересохшей коже молекулы коллагена сшиваются поперечными связями, их боковые цепи находятся в напряжённом деформированном состоянии. По мере увлажнения коллагена это напряжение снимается, цепи распрямляются (Никитина, 1973, с. 79). Наиболее вредно для сохранности кожаных предметов чередование циклов увлажнения и высыхания - чем чаще повторяется цикл увлажнение-высыхание, тем больше повреждений происходит в кожевом материале и тем труднее вернуть коже пластичность (Синицина, Соломатина, 2010, c. 406).

В литературе можно найти множество рекомендаций по сохранению или восстановлению пластических свойств кожевенного материала. При недостатке знаний и опыта ориентироваться в их разнообразии сложно. Кроме того, некоторые из опубликованных методик специалистами-реставраторами в настоящий момент уже не применяются в научной консервации археологических предметов из кожи, о чем не специалист может и не знать. Также, следует помнить и о том, что каждый, требующий реставрации предмет, индивидуален как по технике исполнения, так и по степени сохранности.

В последние годы в ходе археологических работ в историческом центре г. Перми, проводимых Камской археологической экспедицией, найдено значительное количество фрагментов кожаной обуви. Для полноценной дальнейшей работы с ними в первую очередь требуется провести их консервацию. Ключевым моментом является выбор методики консервации.

Не существует единой утвержденной методики реставрации археологической кожи. Для выбора методики необходимо проведение комплекса исследований, которые проверят существующие методики и научно обоснуют их состоятельность (Синицина, Соломатина, 2010 , с. 406). Поэтому в наше время ответственность за выбор методики полностью лежит на исполнителе работ, а выбор зависит от личного практического опыта и знаний в сфере материаловедения. В настоящей статье методики консервации археологических изделий из кожи разделены на методики устаревшие и рекомендованные. Такое деление основано на личном реставрационном опыте автора, подкрепленном стажировками в Государственном Эрмитаже и обучением в магистратуре Казанского (Приволжского) Федерального Университета. Методики, названные в статье рекомендованными, в наши дни применяются практикующими реставраторами, и рекомендуются ими для применения в реставрации археологических изделий из кожи стажерам и студентам в процессе обучения.

Устаревшие методики. На протяжении XX века были опробованы разнообразные методики консервации археологических изделий из кожи. Часть из них уже не применяется в наше время профессиональными реставраторами в научной реставрации, и это основано на расширении знаний о физических и химических свойствах реставрируемого материала и особенностях материалов применяемых в реставрационных целях. Ниже приводятся некоторые из устаревших методик.

В известном издании профессора Фармаковского М.В. «Консервация и реставрация музейных коллекций» 1947-го года рекомендуются следующие методики консервации кожи. Пересохшую кожу нужно насытить водой, для чего берут 5\% водный раствор поваренной соли и в этом растворе вымачивают кожаный предмет до тех пор, пока кожа не станет мягкой. Предполагалось, что соль, во-первых, обеззараживает кожевенный материал, а во-вторых, в перспективе, будет натягивать в кожу влагу из воздуха. После вымачивания в соляном растворе кожу промывают в воде, иначе высохшая на поверхности соль кристаллизуется и может порвать кожу. После этих операций кожу жируют (Фармаковский, 1947, с. 104).

Другой вариант предполагает погружение кожаного предмета в водный раствор из комбинации 5\% поваренной соли и 50\% глицерина. После вымачивания, чтобы компенсировать недостаток жиров, в кожу вводится касторовое масло или ланолин. Ланолин нужно смешивать с не высыхающим маслом, к примеру, касторовым (Фармаковский, 1947 , c. 104). 
Также археологические кожаные вещи можно размягчить выдерживанием в эмульсии состоящей из 50 частей воды, 30 частей спирта, 20 частей касторового масла и 4 частей тимола. Размягченную кожу смазывают ланолином или чистым вазелином (Фармаковский, 1947, c. 104).

Для тонких кож, мехов, кишечного материала рекомендуют эмульсию из глицерина, воды (1:1) и яичного желтка (2-3 желтка на 1 литр жидкости) (Фармаковский, 1947, с. 104). В качестве антисептиков рекомендуются к применению тимол и фенол, сернокислый цинк и салициловая кислота (Фармаковский, 1947 , c. 105).

В 1958 году, со ссылкой на работы Государственного Эрмитажа, Музея этнографии народов СССР и Ленинградского отделения института истории материальной культуры АН СССР, была опубликована методика применения поливинилового спирта для консервации кожи. На $100 \mathrm{~cm}^{3}$ воды берется 0,7-2,5 г поливинилового спирта (в зависимости от состояния, строения и способов обработки кожи) и 40-42 см$^{3}$ глицерина. Изделия из кожи обрабатываются путем аккуратного втирания раствора мягкими тампонами, или, если позволяет сохранность кожи, путем погружения в него. После пропитки и испарения воды кожа жируется втиранием ланолина, или копытного масла. В публикации упоминается, что этот способ консервации можно применять на влажной коже (Румянцев, 1958, c. 101). В издании 1990 года «Химия в реставрации» также упоминается возможность обработки влажной кожи 5-10\% поливиниловым спиртом (ПВС) с добавлением глицерина (Никитин, Мельникова, 1990, с. 264).

Кожу в полуистлевшем состоянии рекомендуют закреплять $2 \%$ раствором поливинилбутираля (ПВБ) (Кирьянов, 1960, с. 83). Но применение ПВБ для консервации кожи противоречит главной цели, которую следует иметь в виду, работая с археологической кожей, а именно - «Главная и самая сложная задача реставраторов попытаться вернуть коже пластичность» (Синицына, Соломатина, 2010, с. 405). Растворителем для поливинилбутираля является этиловый спирт, обладающий дубящими свойствами, попадая в структуру кожи, он будет обезвоживать кожу, способствовать ее пересушиванию.
Следует отметить, что мнение о пользе применения к археологической коже касторового масла очень распространено. Как уже упоминалось, касторовое масло использовалось в середине XX в. и продолжает использоваться и в наши дни, но, в основном, как метод полевой консервации археологических изделий из кожи. Например, в публикации 2010 года «Первичная консервация находок из кожи в полевых условиях археологических экспедиций» В.А. Тупицына предлагает следующие методики. Кожу перед сушкой рекомендовано многократно пропитывать касторовым маслом, а затем высушивать под грузом (Тупицына, 2010, с. 48). Касторовое масло используется и как самостоятельное средство консервации кожи, и как жирующее после использования других консервирующих средств, к примеру, после пластификации кожи в 38\% формалине (Тупицына, 2010, с. 48). Но еще в 1926 г. Фармаковский М.В. описывал дубящие свойства формалина и добавлял его к животному клею, чтобы лишить клей водорастворимости (Красников, Фармаковский, 1926, с.89), а в издании 1946 г. категорически предостерегал от использования формалина в реставрации кожи «Недопустим для кожи всех типов формалин» (Фармаковский, 1947, с. 105). Дубящие свойства формалина противоречат цели пластификации кожи. В этой же публикации рекомендуется выдерживать кожу в эмульсии, состоящей из 50 частей воды, 30 частей этилового спирта, 20 частей касторового масла и 4 частей тимола. После вымачивания в такой эмульсии кожу подсушивают и пропитывают копытным маслом. Другой предложенный способ предполагает вымачивание кожи в течение 12 часов в эмульсии из стружки дегтярного мыла и антисептического мыла «Safeguard» взбитых в смеси этилового спирта и дистиллированной воды (50\%) и глицерина (10\%). При этом достигается первичная пластификация кожи, размягчение ее оксидированных жирующих компонентов, дезинфекция и переход загрязнений из кожи в раствор (Тупицына, 2010, с. 49). Также, приводится способ, заимствованный из практики судебной медицины. В этом случае кожаный предмет пропитывается смесью из диметилсульфоксида, глицерина, 96\%-го этилового спирта, формалина и дистиллированной воды, после чего предмет 
следует завернуть в гигроскопичную ткань, пропитанную этим составом, и завернуть в водонепроницаемую пленку. Так кожа сохраняет все технические характеристики необходимые для исследования (Тупицына, 2010, с. 49). Еще один метод, приведенный в публикации, предполагает обработку кожи раствором, состоящим из 50 мл ледяной уксусной кислоты, 100 мл 96\%-го этилового спирта и 500 мл дистиллированной воды. Вместо ледяной уксусной кислоты можно использовать обычную уксусную кислоту (80\%). После этой обработки кожа восстанавливает пластичность, приобретает первоначальные формы и размеры (Тупицына, 2010, с. 49).

Рекомендованные методики. В 1973 году в статье «Опыт реставрации сухого археологического меха» реставраторы Государственного Эрмитажа К.Ф. Никитина и Т.А. Баранова описали методику смягчения и жирования кожи с применением эмульсии «РК» и ВА-2ЭГА. Кожа, из которой был изготовлен описанный в статье предмет, была сильно пересушена. Проблема заключается в том, что пока не произошло увлажнение пересушенной кожи, никакое жирующее вещество, которое удерживает волокна кожи от склеивания, не поможет. Авторами публикации описан опыт работы с кожей такой сохранности, в ходе которой была применена эмульсия (Никитина, Баранова, 1973, с. 79). В состав эмульсии «РК» входят следующие компоненты: стеарин (вещество химически стабильное), ланолин (шерстный жир), вазелиновое масло (нефтяной продукт), спирт кашалотового жира (цетиловый), глицерин и триэтаноламин (Никитина, Баранова, 1973, с. 78). ВА-2ЭГА (сополимер винилацетата с 2-этилгексилакрилатом) это акриловый сополимер, дающий пластичную пленку, используется для консолидации разрушенного кожевенного материала (является разработкой ГОСНИИРа, в настоящий момент не выпускается). В ходе реставрационных работ очищенную кожу пропитывали 10-12\% ВА-2ЭГА 2-3 раза. Затем наносили 2-3 слоя жирующей эмульсии «РК». «Составы вминали в кожу пальцами, массирующими движениями расправляя покоробленные, смятые и слежавшиеся места. В результате такой обработки дерма стала мягкой и эластичной, что позволило, соблюдая необходимую осторожность, расправить даже места резких сгибов» (Никитина, Баранова, 1973, с. 79).

Несмотря на то, что методика опубликована в 1978 году, но и в 2004 году она продолжает быть актуальна, и применяется для консервации археологических предметов из кожи (Швец, 2013, с. 375).

Проводить увлажнение на пересушенных кожах, длительное время находившихся в условиях музейных или иных хранений, нужно осторожно. Лучше всего для работы над предметами подобной сохранности зарекомендовало себя одновременное применение процессов консервации и влажной расчистки. Методика в основных моментах перекликается с описанной выше, но используются другие материалы - раствор этилового спирта, воды и глицерин (соответственно, 10\%:60\%:30\%) с добавлением антисептика, который применяется для расчистки, увлажнения и консервации кожевенной ткани. После такой обработки проводится жирование ланолиновой эмульсией, состоящей из этилового спирта, глицерина, ланолина, нейтрального мыла и дистиллированной воды (Федан, Богатова, Буршнева, 2019, с. 363).

Методы консервации полиэтиленгликолями разных молекулярных масс. Консервация археологической кожи с применением полиэтиленгликолей различных молекулярных масс применяется для влажных, специально увлажненных, либо извлеченных из мокрых раскопов, кожаных предметов.

Самое раннее упоминание о применении полиэтиленгликолей различных молекулярных масс в отечественное литературе автору статьи встретилось в уже упоминавшемся издании 1990 года «Химия в реставрации». В нем для смягчения старых разрушенных кож рекомендуется помещать кожаные предметы в раствор, содержащий в одном литре дистиллированной воды 40 грамм ПЭГ-400 и 125 грамм ПЭГ 1500 (Никитин, Мельникова, 1990, С. 265).

Следует отметить, что в отечественной литературе описано значительное количество вариантов использования полиэтиленгликолей различных молекулярных масс. Отличие их друг от друга заключается, в основном, в использовании различных комбинаций ПЭГов. Так, растворы для погружения кожи могут быть приготовлены из ПЭГа 300 и 
ПЭГа 1500, или ПЭГа 400 и ПЭГа 3000. Либо, как вариант, на первом этапе происходит погружение предмета в раствор с ПЭГом 400, затем проводится его сушка вымораживанием, после чего предмет погружается в раствор высокомолекулярного ПЭГа. Разница присутствует и в процентном содержании действующих веществ в растворах. Кроме того, одни специалисты по реставрации кожи жируют кожевенный материал после сушки вымораживанием, а другие в процессе вымораживания. Разница в методиках зависит от сохранности консервируемого материала и личного практического опыта специалиста выполняющего работы по консервации.

Наиболее распространенный рецепт для пластификации археологической кожи погружение материала в водный раствор ПЭГ 300 и ПЭГ 1500. Срок, на который предмет погружается в раствор практически невозможно предсказать. Пропитку заканчивают, когда материал становится пластичным. Этот процесс может потребовать значительного времени - это может быть месяц, а может и шесть месяцев (Синицына, Соломатина, 2010, с. 406). Н.П. Синицина рекомендует для первичной (полевой) консервации археологических находок поместить предмет из кожи, после механической очистки, в раствор, содержащий ПЭГ 300 - 20\%, ПЭГ 1500 - 10\%, этиловый спирт с превентолом 10\%, дистиллированная вода $60 \%$. Такая консервация призвана, в дальнейшем, облегчить задачу реставратора (Синицина, 2005, с. 128).

Продолжительность пластификации зависит от изначальной сохранности предмета. Так, в статье Н.П. Синицыной и Н.В. Соломатиной «Реставрация кожаных предметов археологического происхождения» приводится пример работы с кожаной сумочкой, имеющей хорошую сохранность, которая поступила в работу во влажном состоянии. Пластификация деталей сумки проводилась методом погружения в водный раствор ПЭГ 400 (15\%) и ПЭГ $4000(3 \%)$ на 7 дней, затем в раствор ПЭГ 400 (30\%) и ПЭГ 4000 (5\%) - на 7 дней. После этого предмет был помещен на месяц в морозильную камеру при температуре $-10^{\circ} \mathrm{C}$ (Синицына, Соломатина, 2010, с. 407). Авторами также отмечается, что при «наличии оборудования практикуется вакуумное сушение сублимацией, но и не вакуумное сушение сублимацией дает хороший результат, хотя и требует больше времени» (Синицына, Соломатина, 2010, с. 407).

Методики консервации полиэтиленгликолями разных молекулярных масс применялись и в реставрации археологических кожаных предметов из раскопок Московского Кремля. Ниже представлены некоторые из них.

В статье Т.А. Левыкиной «Консервация и реконструкция археологических памятников из кожи (на примере реставрации обуви)» описан пример реставрации сапожка удовлетворительной сохранности из раскопок Московского Кремля. Кожа, из которой изготовлен предмет, пластифицирована сначала в растворе ПЭГ 400 (40\%), ПЭГ 1500 (5\%), дистиллированная вода (55\%). Кожаные фрагменты погружались в данный раствор на 2 недели. Затем был использован раствор ПЭГ 400 (30\%), ПЭГ 1500 (20\%), дистиллированная вода $(50 \%)$ в который фрагменты предмета погружались на три недели. По мере размягчения загрязнения убирались скальпелем, а раствор заменялся на чистый. После изъятия из раствора детали были просушены фильтровальной бумагой и помещены в морозильную камеру на неделю при температуре $-6-(-10)^{0}$ С. Затем следовало смягчение смазками: с криоланом (криолан 20 г, вазелиновое масло 50 мл, пчелиный воск 1 г) и Cire 213 (Левыкина, 2010, с. 353).

Другой описанный в публикации Т.А. Левыкиной предмет - лапоть с кожаными и лыковыми ремешками, кожаные детали которого имели удовлетворительную сохранность. После пластификации в растворе ПЭГ 400 (30\%), ПЭГ 1500 (20\%) и дистиллированной воды (50\%), кожаные фрагменты предмета были помещены в раствор ПЭГ 400 (30\%), ПЭГ $3000(25 \%)$ и дистиллированной воды (45\%) на 1,5 недели. Затем кожаные фрагменты предмета были помещены в морозильную камеру с температурой $-6-(-10)^{0} \mathrm{C}$ на неделю (Левыкина, 2010, с. 355).

В ряде случаев реставраторами применяется водно-спиртовой раствор ПЭГ. Например, О.Л. Швец описывает реставрацию сапог из погребения могильника Горноправдинский (XIX в.), которые промывались погружением в раствор дистиллированной воды (50\%), этилового спирта (40\%), ПЭГ 400 (5\%) и антисептика (5\%). Затем, на протяжении шести 
недель проводилось укрепление предмета 20\% водным раствором ПЭГ 400 с антисептиком. Постепенно концентрация раствора повышалась и к концу 6 недели достигла 60\%. Закрепление материала проводилась следующим способом: когда концентрация ПЭГ 400 достигла 50\% в раствор начали вводить ПЭГ 1500, конечная концентрация которого к концу 3 недели составила 10\%. Через 9 недель началась сушка вымораживанием (при температуре минус $4-7^{0} \mathrm{C}$ ) с одновременным нанесением жирующего вещества. На третьей неделе вымораживания кистью начали наносить жирующий состав - ланолин (55\%), вазелиновое масло (40\%), пчелиный воск (5\%). Жирующее вещество вводилось ежедневно на протяжении 8 недель. После сушки голенища сапога уложили под мягкий и легкий пресс между слоями фильтровальной бумаги (Швец, 2011, с. 318).

В ходе работы над предметами с пересохшей кожей, рекомендована следующая методика. Первоначально производится чистка, а также увлажнение и пластификация с применением водного раствора ПЭГ 400. Затем, следует полное погружение предмета в водный раствор ПЭГ 400 для укрепления микроструктуры кожи и дальнейшей пластификации, после чего следует закрепление микроструктуры и пластичности комбинацией водных растворов ПЭГ 400 и ПЭГ 1500. И, в завершение, проводится сушка в морозильной камере с одновременным нанесением жирующих смазок (Швец, 2013, с. 377).

В настоящее время применение полиэтиленгликолей в реставрации археологических изделий из кожи является самым предпочтительным вариантом - приобрести ПЭГ не составляет сложностей, результаты работы вполне соответствуют поставленным целям. Самое главное - это наработать опыт, т.к. выбор комбинации ПЭГов, длительности вымачивания и просушки осуществляется на уровне ощущений реставратора выполняющего работу. Ниже приведен опыт автора статьи по применению ПЭГа в консервации фрагментов кожаной археологической обуви.

Консервация с применением комбинации ПЭГов на примере работы с фрагментами кожаной обуви из раскопок в г. Перми 2020 г. Летом 2020 года в г. Перми были проведены раскопки памятника археологии
«Егошихинский медеплавильный завод, поселение», датированного 1723-1842 гг. Раскопки проводила Камская археологическая экспедиция, руководила работой Л.В. Романова. В ходе раскопок обнаружено значительное количество обуви и ее фрагментов, а также деталей кожаных изделий, атрибуция которых в настоящее время не ясна.

Предметы были извлечены во влажном состоянии из обильно насыщенного грунтовыми водами слоя темно-серой супеси с включениями древесной щепы, строительного мусора и навоза (рис.1). Первичная очистка проводилась водопроводной водой, после чего предметы были упакованы в полиэтилен и отправлены на хранение в холодильник. Только спустя 4 месяца предметы поступили в реставрационную мастерскую Пермского краеведческого музея.

Ниже в статье описаны консервационные мероприятия на примере работы с деталями одного изделия - полупары котов. Коты - обувь характерная для жителей Пермского края. Традиционно коты состоят из головки, подошвы, тканевой обшивки верха и пяточной петли для продергивания оборы.

Полученный в реставрацию предмет состоял из головки с заплаткой для носочной части, подошвы с заплатой на носочную часть, фрагментов стельки и пяточной петли (рис.2). Кожа головки декорирована линованием. Предмет поступил в работу влажным, но некоторые части уже начали подсыхать. Головка была сплющена, образовавшиеся заломы по боковым краям головки были жесткими. В пяточной части головки присутствовала деформация кожи по принципу гармошки. При составлении программы реставрации было принято решение не исправлять эти заломы, так как они, вероятно, являются естественным результатом бытования предмета.

Значительные почвенные загрязнения присутствовали как на бахтармяной стороне кожи, так и на мерее. Загрязнения, по возможности, были очищены всухую щетинными кистями разной жесткости. В процессе расчистки в отверстиях от швов были обнаружены фрагменты нитей из растительного волокна.

Для консервационной пропитки детали предмета и их фрагменты были погружены 
в раствор, содержащий ПЭГ 400 - 20\%, ПЭГ $1500-10 \%$, спирт этиловый - 10\%, дистиллированная вода с катамином АБ $-60 \%$. Тонкие и разрушенные детали и их фрагменты погружались в раствор на сетке, закрепленной в пластиковых пяльцах.

Через десять дней обработки детали предмета и их фрагменты были осмотрены - плесени не появилось, кожа стала мягкой, но жесткие заломы/сгибы головки остались, раствор загрязнен не сильно. Было выполнено шерфование кожи с бахтармяной стороны скальпелем в пропиточном растворе, что позволило дополнительно очистить поверхность материала, а также частично извлечь загрязнения из толщи материала. После очистки детали предмета помещены в чистый раствор, аналогичный описанному выше. При этом, заломы на головке были расправлены и слегка зафиксированы грузами.

Спустя пять недель после первого погружения фрагментов в раствор все фрагменты (за исключением головки) были извлечены из раствора, слегка обсушены в естественных условиях, упакованы в фильтровальную бумагу и убраны в морозильную камеру бытового холодильника для просушки вымораживанием при температуре $-5^{\circ} \mathrm{C}$. В ходе пропитки детали стельки были разделены на две части, а от подошвы был отделен фрагмент стельки. На тот момент, кожа головки обуви оставалась недостаточно пластичной, поэтому предмет был оставлен в растворе еще на неделю. Затем и головка была извлечена из раствора, упакована в фильтровальную бумагу и помещена в морозильную камеру. Все детали были выдержаны в морозильной камере четыре недели, бумага заменялась на сухую каждую неделю.

После извлечения из морозильной камеры было проведено жирование и одновременное придание формы. Для жирования была приготовлена смазка из ланолина (5 г), глицерина (5 мл), уайт-спирита (25 мл), вазелинового масла (15 г) и дистиллированной воды (50 мл). Положительный опыт работы данной смазкой, без указания пропорций, ранее опубликован в статье 3.А. Ивановой, А.А. Ткачева «Методы и приемы жирования кожи на примере погре- бальных комплексов Тазовского Заполярья» (Иванова, Ткачев, 2019). Пропорции компонентов смазки были представлены руководителем практического курса по реставрации изделий из кожи в рамках магистерской программы «Реставрация историко-культурного наследия» К(П)ФУ, ведущим художником-реставратором ИАЭт СОРАН Швец О.Л., в котором принимал участие автор данной статьи. Смазка очень удобна в работе - легко готовится и не оставляет липкого жирного слоя на поверхности обрабатываемого материала. Достаточно было 4-6 подходов к каждому фрагменту, в зависимости от толщины кожи. Форма фиксировалась легкими грузиками, бельевыми прищепками через прокладки из толстой фторопластовой пленки (рис. 3-8).

В дальнейшем предстоит продублировать разрывы и собрать предмет.

Из полученного в ходе работ опыта можно сделать следующие практические выводы.

Применение комбинации ПЭГов на первоначальном этапе работ оказалось недостаточно эффективным для данного предмета. Вероятно, нужно было начинать с раствора ПЭГ 400 , что облегчило бы проникновение ПЭГа в толщу материала. А затем уже добавлять ПЭГ 1500.

Кожа головки предмета, к моменту поступления в реставрацию, по видимому, была не достаточно влажной и поэтому процесс ее пропитки шел хуже, чем остальных деталей и пришлось применять грузы для исправления деформации в процессе пропитки. Вероятно, кожаные фрагменты, находящиеся в подобном состоянии, необходимо дополнительно увлажнять перед погружением в раствор ПЭГ.

Успешная реставрация археологических изделий из кожи, как и реставрация любых других памятников, требует практического опыта. Кожа настолько непростой материал, что именно личный практический опыт особенно важен. Не лишним будет повторить, что нет единого рецепта для реставрации предметов из кожи различной степени сохранности и в каждом конкретном случае требуется индивидуальный подход (Синицина, 2005, с. 128).

\section{ЛИТЕРАТУРА}

Иванова 3.А., Ткачева А.А. Методы и приемы жирования кожи на примере погребальных комплексов Тазовского Заполярья // Коллоквиум молодых реставраторов RESCON-2019: материалы Всерос- 
сийской научно-практической молодежной конференции (Казань, 25-27 ноября 2019 г.) / науч.ред. С.Г. Буршнева. Казань: Изд-во Казан. ун-та, 2019. С. 38-41.

Красников И.П., Фармаковский М.В. Керамика, ее техника и сохранение / Материалы по методологии археологической технологии. Вып. 6. Л.: ГАИМК, 1926, 100 с.

Кимеева Т.В., Окунева И.В. Основы консервации и реставрации археологических и этнографических музейных предметов. Кемерово: КемГУКИ, 2009. 251 с.

Кирьянов А.В. Реставрация археологических предметов. М.: АН СССР, 1960. 95 с.

Левыкина T.A. Консервация и реконструкция археологических памятников из кожи (на примере реставрации обуви) // Интеграция археологических и этнографических исследований: сборник научных трудов / Отв. ред. Н.А. Томилов, М.Л. Бережнова, С.Н. Корусенко, Р.С. Хакимов. Ч. 1. Казань: Институт истории им. Ш. Марджани АН РТ; Иркутск-Омск, 2010. С. 352-357.

Никитин М.К., Мельникова Е.П. Химия в реставрации. Справочное пособие. Л.: Химия, 1990. 293 с.

Никитина К.Ф., Баранова Т.А. Опыт реставрации сухого археологического меха // СГЭ. Вып. XXXVII. Л: Аврора, 1973. С. 78-79.

Румянцев Е.Л. Один из способов консервации кожи // КСИИМК. Вып.72. М: АН СССР, 1958. С. 100-102.

Синищьлна Н.П. Некоторые проблемы реставрации археологической кожи // Грабаревские чтения. Вып. VI. / сост. С. Ф. Вигасина. М.: Сканрус, 2005. С. 118-128.

Синицына Н.П., Соломатина Н.В. Реставрация кожаных предметов археологического происхождения // Интеграция археологических и этнографических исследований: сборник научных трудов / Отв. ред. Н.А. Томилов, М.Л. Бережнова, С.Н. Корусенко, Р.С. Хакимов. Ч. 1. Казань: Институт истории им. Ш. Марджани АН РТ; Иркутск-Омск, 2010. С. 405-410.

Тупицына B.A. Первичная консервация находок из кожи в полевых условиях археологических экспедиций // Интеграция археологических и этнографических исследований: сборник научных трудов / Отв. ред. Н.А. Томилов, М.Л. Бережнова, С.Н. Корусенко, Р.С. Хакимов. Ч. 1. Казань: Институт истории им. Ш. Марджани АН РТ; Иркутск-Омск, 2010. С. 48-49.

Фармаковский М.В. Консервация и реставрация музейных коллекций. М.: Типография «Красный печатник», 1947. 144 с.

Федан П.В., Богатова Л.Ф., Буршнева С.Г. Опыт обучения реставраторов по программе интенсива «Консервация и реставрация археологической кожи на базе магистратуры К(П)ФУ по профилю «Реставрация историко-культурного наследия) // Археология Евразийских степей. 2019. № 5. С. 261-267.

Швец О.Л. Консервация и реставрация археологических кожаных предметов из могильника Горноправдинского (ХМАО-Югра) // Ханты-Мансийский автономный округ в зеркале прошлого. Вып. 9 / Отв. ред.: А.Я. Яковлев. Томск; Ханты-Мансийск: Изд-во ТГУ 2011. С.311-323.

Швец О.Л. Подбор метода консервации «великовозрастной» кожи (по материалам могильника Уландрык I) // Проблемы археологии, этнографии, антропологии Сибири и сопредельных территорий. Материалы итоговой сессии института археологии и этнографии СО РАН, 2013, т. ХІХ. / Отв. ред. А.П. Деревянко, В.И. Молодин. Новосибирск: Изд-во Института археологии и этнографии СО РАН, 2013. С. 374-377.

\section{Информация об авторе:}

Чурилова Наталия Анатольевна, заведующий реставрационными мастерскими, ГКБУК «Пермский краеведческий музей» (г. Пермь, Россия); pkmrestavr@yandex.ru

\section{REFERENCES}

Ivanova, Z. A., Tkacheva, A. A. 2019. In Burshneva, S. G. (ed.). Kollokvium molodykh restavratorov RESCON-2019 (RESCON-2019 Colloquium of Young Restorers). Kazan: Kazan Federal University, 38-41 (in Russian).

Krasnikov, I. P., Farmakovskii, M. V. 1926. Keramika, ee tekhnika i sokhranenie (Pottery, Technique and Preservation). Series: Materialy po metodologii arkheologicheskoi tekhnologii (Materials on the Methodology of Archaeological Technology) 6. Leningrad: State Academy for the History of Material Culture (in Russian).

Kimeeva, T. V., Okuneva, I. V. 2009. Osnovy konservatsii $i$ restavratsii arkheologicheskikh $i$ etnograficheskikh muzeinykh predmetov (Fundamentals of the Conservation and Restoration of Archaeological and Ethnographic Museum Items). Kemerovo: Kemerovo State Institute of Culture (in Russian).

Kir'ianov, A. V. 1960. Restavratsiia arkheologicheskikh predmetov (Restoration of Archaeological Objects). Moscow: Academy of Sciences of the USSR (in Russian). 
Levykina, T. A. 2010. In Tomilov, N. A., Berezhnova, M. L., Korusenko, S. N., Khakimov, R. S. (eds.). Integratsiia arkheologicheskikh $i$ etnograficheskikh issledovanii (Integration of Archaeological and Ethnographic Studies) 1. Kazan: Institute of History named after Sh. Mardzhani, Tatarstan Academy of Sciences; Irkutsk; Omsk, 352-357 (in Russian).

Nikitin, M. K., Mel'nikova, E. P. 1990. Khimiia v restavratsii (Chemistry in Restoration). Leningrad: "Khimiia" Publ. (in Russian).

Nikitina, K. F. 1973. In Soobshcheniia Gosudarstvennogo Ermitazha (Reports of the State Hermitage Museum) 37. Leningrad: "Avrora" Publ., 78-79 (in Russian).

Rumyantseva, E. L. 1958. In Kratkie soobshcheniia Instituta istorii material'noi kul'tury (Brief Communications of the Institute for the History of Material Culture) 72. Moscow-Leningrad: Academy of Sciences of the USSR, 100-102 (in Russian).

Sinitsina, N. P. 2005. In Vigasina, S.F. (comp.). Grabarevskie chteniia (Grabarev Readings). 4. Moscow: "Skanrus" Publ., 118-128 (in Russian).

Sinitsina, N. P., Solomatina, N. V. 2010. In Tomilov, N. A., Berezhnova, M. L., Korusenko, S. N., Khakimov, R. S. (eds.). Integratsiia arkheologicheskikh i etnograficheskikh issledovanii (Integration of Archaeological and Ethnographic Studies) 1. Kazan: Institute of History named after Sh. Mardzhani, Tatarstan Academy of Sciences; Irkutsk; Omsk, 405-410 (in Russian).

Tupitsina, V. A. 2010. In Tomilov, N. A., Berezhnova, M. L., Korusenko, S. N., Khakimov, R. S. (eds.). Integratsiia arkheologicheskikh $i$ etnograficheskikh issledovanii (Integration of Archaeological and Ethnographic Studies) 1. Kazan: Institute of History named after Sh. Mardzhani, Tatarstan Academy of Sciences; Irkutsk; Omsk, 48-49 (in Russian).

Farmakovsky, M. V. 1947. Konservatsija i restavratsija muzeinykh kollektsii (Conservation and Restoration of Museum Collections). Moscow: "Krasnyi pechatnik" Publ. (in Russian).

Fedan, P. V., Bogatova, L. F., Burshneva, S. G. 2019. In Arkheologiia Evraziiskikh stepei (Archaeology of Eurasian Steppes) 5. 261-267 (in Russian).

Shvets, O. L. 2011. In Yakovlev, A. Ya. (ed.). Khanty-Mansiyskiy avtonomniy okrug v zerkale proshlogo (Khanty-Mansi Autonomous Area in the Mirror of the Past) (9). Tomsk; Khanty-Mansiysk: Tomsk State University, 84-107 (in Russian).

Shvets, O. L. 2013. In Derevianko, A. P., Molodin, V. I. (eds.). Problemy arkheologii, etnografii, antropologii Sibiri i sopredel'nykh territorii (Issues of Archaeology, Etnography and Anthropology of Siberia and the Adjoining Territories). 19. Novosibirsk: Institute of Archaeology and Ethnography of the Siberian Branch, Russian Academy of Sciences, 374-377 (in Russian).

\section{About the Author:}

Churilova Natalia A. Perm Museum of Local Lore. Monastyrskaia St., 11, Perm, 614000, Russian Federation; pkmrestavr@yandex.ru 